\title{
Control of antibiotic-resistant bacteria in the office and clinic
}

\section{Anne G. Matlow MD, Shaun K. Morris MD MPH}

I nfections with antibiotic-resistant bacteria, including methicillin-resistant Staphylococcus aureus (MRSA), vancomycin-resistant Enterococcus and Clostridium difficile, are usually considered hazards of inpatient care. However, the potential to acquire these organisms is not restricted to the acute or long-term care setting. Ambulatory care procedures, such as dialysis, and follow-up of patients who acquired these organisms while in hospital can make some outpatient settings microcosms of inpatient care. The recent emergence of community-associated MRSA, ${ }^{1,2}$ vancomycin-resistant Enterococcus ${ }^{3}$ and $C$. difficile $^{4}$ among patients with no known predisposing factors has increased the potential for offices and clinics to become silent reservoirs of these pathogens.

The risk of infection transmission in the office or clinic is lower than in the hospital because of fewer encounters, shorter contact times and exposure to a smaller number of bacteria. ${ }^{5}$ However, the consequences may be similar because the therapeutic options are limited and outcomes of some infections may be worse. This will affect mostly patients with underlying diseases, including immunosuppression, given their increased risk for infection, admission to hospital and need for invasive devices. In most ambulatory settings, general measures of infection control are sufficient to prevent transmission. However, if the patient population is more vulnerable, the index patient is heavily colonized or ongoing transmission is demonstrated, more intensive measures may be necessary.

\section{Modes and risk of transmission in the outpatient setting}

MRSA, vancomycin-resistant Enterococcus and C. difficile are most commonly transmitted by direct contact via contaminated people or indirect contact via contaminated objects). ${ }^{6-8}$ Less commonly, MRSA can be transmitted by expectorated respiratory secretions, such as from patients with cystic fibrosis. ${ }^{9}$ Up to $6 \%$ of individuals with nasal colonization by $S$. aureus who have concurrent rhinovirus infection may disperse high numbers of the bacterium into the environment ("cloud" syndrome). ${ }^{10}$

There are few studies documenting the spread of MRSA, vancomycin-resistant Enterococcus or C. difficile in offices or clinics. A single report describes MRSA transmission in a clinic for HIV-infected patients. Two health care workers developed MRSA soft-tissue infections with the same strain of community-associated MRSA cultured from environmental

\section{Key points}

- Hand hygiene and judicious use of antibiotics are essential for infection control.

- Patients should use an alcohol-based hand rub on arrival in the office or clinic.

- Health care workers should use an alcohol-based hand rub or soap and water before and after contact with patients.

- Better identification of the risk factors for transmission of resistant organisms is required in ambulatory care settings.

specimens, suggesting the role of contaminated inanimate objects in transmission. ${ }^{11}$ The potential role of the environment in outpatient transmission is further supported by the isolation of MRSA from 2 of 9 outpatient chiropractic adjustment tables. ${ }^{12}$

Evidence for the transmission of vancomycin-resistant $E n$ terococcus among outpatients is more robust, particularly among those receiving dialysis. Vancomycin-resistant Enterococcus was acquired by $17.8 \%$ of patients receiving outpatient peritoneal dialysis or hemodialysis, which correlated with vancomycin use in the outpatient setting. ${ }^{13}$ Eleven oncology patients with vancomycin-resistant Enterococcus reportedly contaminated the environment in $29 \%$ of health care encounters. ${ }^{14}$ In a study involving fecally continent patients, the hands of $36 \%$ of patients were colonized with vancomycin-resistant Enterococcus. ${ }^{15}$ Patients in this study contaminated $58 \%$ of chairs from hemodialysis sessions, $48 \%$ of couches from outpatient consultation sessions and $20 \%$ of health care worker gowns. ${ }^{15}$ Patients previously colonized with vancomycin-resistant Enterococcus can still contaminate the environment, although less frequently than those currently colonized..$^{15}$ Incontinent patients may contaminate the outpatient environment more than continent patients. ${ }^{16}$

Patients with $C$. difficile in ambulatory-care settings may include those presenting for follow-up after diagnosis in hospital, those whose infection became apparent after discharge and those who acquired $C$. difficile in the community. Community-acquired cases may be idiopathic or may result from antibiotics administered in outpatient care. In Seattle, the prevalence of $C$. difficile disease among people receiving ambulatory care was 12 infections per 100000 person-years and was correlated with the use of cephalexin and cefixime. ${ }^{17}$

From the Infection Prevention and Control Program (Matlow) and the Division of Infectious Diseases, Department of Pediatrics (Matlow, Morris), Hospital for Sick Children; and the University of Toronto (Matlow, Morris), Toronto, Ont. 
Table 1: Survival of methicillin-resistant Staphylococcus aureus, vancomycin-resistant Enterococcus and Clostridium difficile on dry inanimate objects ${ }^{18}$

\begin{tabular}{lc}
\hline Bacterium & Duration of survival \\
\hline Methicillin-resistant S. aureus & 7 days to 7 months \\
Vancomycin-resistant Enterococcus & 5 days to 4 months \\
C. difficile spores & 5 months \\
\hline
\end{tabular}

Contamination of $C$. difficile within an outpatient facility has not been described but is theoretically possible.

Higher numbers of bacteria or widespread contamination facilitates transmission of MRSA, vancomycin-resistant Enterococcus and $C$. difficile. Patients with draining wounds or abscesses or with diarrhea or fecal incontinence are more likely than those without these conditions to contaminate the environment. ${ }^{6}$ This increases the risk of spread. ${ }^{6}$

The ability of an organism to be transmitted is also dependent on its ability to survive in the environment. Table 1 describes the persistence of MRSA, vancomycin-resistant Enterococcus and $C$. difficile on inanimate surfaces. ${ }^{18}$ Despite individual patient and microbial factors, health care workers remain the main mode of spread. Therefore, they should remain the primary target of prevention strategies.

\section{Infection prevention and control}

There is little robust science to guide the clinical care of patients with MRSA, vancomycin-resistant Enterococcus and C. difficile in the ambulatory care setting. Most recommendations are based on suggestive clinical or epidemiological studies or theoretical rationale. ${ }^{6-8}$ Recent recommendations for managing drug-resistant pathogens in acute care support a two-tiered approach, with intensified measures in cases of ongoing transmission. Intensified measures are also advocated by some as standard practice in hemodialysis units and cystic fibrosis clinics. ${ }^{79,19}$ Despite this, such infection control measures will rarely be necessary in the office setting.

\section{What should patients do on arrival in the office?}

Patients should be encouraged to decontaminate their hands with an alcohol-based hand sanitizer on arrival. ${ }^{20}$ In cystic fibrosis clinics, patients are advised to practice hand hygiene on arrival and departure from the clinic, because of the number of patients colonized with multidrug-resistant bacteria and the high colonization pressure in this setting. ${ }^{9}$

\section{What should health care workers do?}

Hand hygiene is the most essential element of infection control in any health care setting. Hand hygiene should be performed before and after contact with patients or their environment, before an aseptic procedure, after removing gloves, after exposure to body fluids, and when moving from a contaminated body site to a clean site. ${ }^{6,8,19,21}$ Alcohol-based hand rubs are generally preferred, but soap and water are indicated if no alcohol-based hand rubs are available, if hands are visi- bly dirty, soiled or contaminated with proteinaceous material, or if contact with $C$. difficile spores may have occurred, because alcohol does not kill spores. ${ }^{8}$

Given the lack of evidence for transmission of MRSA and vancomycin-resistant Enterococcus in the outpatient setting, consistent application of routine practices and standard precautions will likely suffice in most environments. Additional contact precautions, such as gown and gloves, should be used when caring for patients with draining abscesses or wounds, uncontained diarrhea, fecal incontinence or cystic fibrosis, and if ongoing transmission has been demonstrated. ${ }^{6-9}$ Active surveillance cultures are not routinely recommended, although they may be indicated if an outbreak or ongoing transmission is suspected. Contact precautions are advised for care of patients with $C$. difficile-associated diarrhea in any health care setting $;{ }^{6,8}$ however, the role of contact precautions has not been validated in the ambulatory care setting. 6.8

Local guidelines and circumstances should determine practice in settings with specialized and vulnerable populations, such as in an oncology or transplant clinic). Hands must be decontaminated with soap and water or an alcohol-based hand sanitizer after gloves are removed. ${ }^{7.8}$

Management guidelines for community-associated MRSA have been published. ${ }^{2}$ Empiric antibiotic treatment targeting S. aureus should cover MRSA if the local prevalence rate of MRSA exceeds $15 \%$ of $S$. aureus strains. ${ }^{22}$ Patients should also be counselled about management in the home.

\section{How should prevention and control be managed?}

Hand hygiene agents should be available to patients and families in the office (Box 1). ${ }^{19}$ Flagging the charts of patients with MRSA or vancomycin-resistant Enterococcus may help determine isolation and treatment practices. ${ }^{8}$ Patients colonized with MRSA or vancomycin-resistant Enterococcus who re-

Box 1: Recommendations to prevent transmission of antimicrobial-resistant bacteria in the office and clinic

- Have alcohol-based hand rubs available for use by patients and health care workers

- Ensure that processes are in place for the identification of colonized or infected patients

- Move colonized or infected patients who have draining abscesses or wounds, uncontained diarrhea, fecal incontinence or cystic fibrosis to an examining room as soon as possible

- Adhere to routine hand-hygiene practices for all patients

- Use contact precautions, such as gown and gloves, when providing care to colonized or infected patients with draining abscesses or wounds, uncontained diarrhea, fecal incontinence or cystic fibrosis, and in situations where ongoing transmission has been demonstrated

- Continue with general housekeeping and equipment cleaning, disinfecting and sterilizing unless transmission in the office is demonstrated, in which case intensified measures may be considered

- Consult with experts, such as public health officials or hospital infection control personnel 
quire contact precautions should be moved to an examination room as soon as possible on arrival in the office..$^{89}$

The principles for cleaning, disinfecting and sterilizing medical equipment, as well as cleaning and disinfecting the environment, are the same as in hospitals. ${ }^{23}$ Germicides containing chlorine have been used in hospitals to prevent transmission of $C$. difficile. ${ }^{24}$ The need for bleach in the ambulatory care setting has not been studied. Each office should develop a regular cleaning program. Although there are no explicit guidelines for the frequency of cleaning, commonly touched surfaces such as door knobs and toilet seats may require frequent cleaning. ${ }^{23}$ The presence of carpet in heavy patient-traffic areas is discouraged because numerous spills are likely. Carpets are also discouraged in areas where immunocompromised patients are likely to stay for extended periods of time (e.g., infusion centres). If carpets are used, periodic deep cleaning is recommended.

Furniture should be easily cleanable, especially in areas where care is provided to high-risk patients and where contamination with bodily fluids is likely (e.g., pediatricians' offices). ${ }^{23}$ Communal toys should not be porous or plush. Toys and magazines that have been mouthed or soiled must be removed from circulation. Toys should ideally be cleaned with a 1:100 bleach solution, washed with soap and water, and air dried between patients or at the end of each day. ${ }^{25,26}$

\section{Strategies to prevent transmission}

A multimodal approach is required to prevent transmission. This includes administrative support, such as policies and guidelines about the identification and triage of patients and isolation precautions, and the availability of personal protective equipment and alcohol-based hand rubs or soap and water. There should also be education about these policies and judicious use of antibiotics. Since most cases of transmission in ambulatory care are a result of deficient infection-control practices, strict adherence to recommendations is paramount. ${ }^{6-8}$

\section{Barriers to implementation}

In hospitals, prioritization of infection prevention and control and patient safety by organizational leaders is associated with better adherence to infection-control practices. ${ }^{27}$ Adherence in ambulatory care settings can be encouraged by demonstrated commitment by the physician or clinic director to infection prevention and control through allocation of financial resources for supplies, such as alcohol-based hand rubs and personal protective equipment, and personnel, such as housekeeping staff. Leaders should demonstrate the appropriate behaviours and ensure that office or clinic personnel are educated and informed. The negative impact of isolation precautions on direct patient contact and adverse events in the inpatient setting are controversial ${ }^{28-31}$ and should not deter practice in ambulatory care. Although barrier precautions may be considered cumbersome, ${ }^{32}$ the outbreak in 2003 of severe acute respiratory syndrome in Toronto, Ontario, underscores the importance of incorporating basic infection-control measures into routine practice. ${ }^{33}$

\section{Knowledge gaps}

The full extent of environmental contamination and transmission of MRSA, vancomycin-resistant Enterococcus and C. difficile in the ambulatory care setting is unknown, in part because of the lack of sensitive and standardized methods to detect and measure environmental contamination. Better identification of risk factors and measurement of the risk are needed. There are no validated data informing which infection control measures should be altered to fit various ambulatory care practices and patient populations. The threshold for intensifying efforts is also unknown. The presence of administrative controls and compliance with recommended infection control measures in various settings and the barriers to compliance have not been fully studied. The impact of barrier precautions and other measures on the interaction between patients and health care worker and patient satisfaction requires further study.

\section{Conclusion}

Evidence suggests that the transmission of MRSA, vancomycinresistant Enterococcus and $C$. difficile in ambulatory care is infrequent. Thus, in most settings, routine infection-control measures are recommended. Ongoing surveillance in general and specialized outpatient settings will help determine the epidemiology of the colonization and infection, whether the pathogenicity of the strains is changing and how to modify infection control practices if required. Regardless, hand hygiene and judicious use of antimicrobials will remain essential elements of prevention and control in the office and clinic setting.

This article has been peer reviewed.

Competing interests: None declared.

Contributors: Both of the authors contributed to the content of the article, revised it critically and approved the final version submitted for publication.

\section{REFERENCES}

1. Boucher HW, Corey GR. Epidemiology of methicillin-resistant Staphylococcus aureus. Clin Infect Dis 2008;46(Suppl 5):S344-9.

2. Barton-Forbes M, Hawkes M, Moore D, et al. Guidelines for the prevention and management of community associated methicillin-resistant Staphylococcus aureus (CA-MRSA): a perspective for Canadian health care practitioners. Can J Infect Dis Med Microbiol 2006;17(Suppl C):1B-24B.

3. D'Agata EM, Jirjis J, Gouldin C, et al. Community dissemination of vancomycinresistant Enterococcus faecium. Am J Infect Control 2001;29:316-20.

4. McFarland LV, Beneda HW, Clarridge JE, et al. Implications of the changing face of Clostridium difficile disease for health care practitioners. Am J Infect Control 2007;35:237-53

5. Nafziger DA, Lundstrom T, Chandra S, et al. Infection control in ambulatory care. Infect Dis Clin North Am 1997;11:279-96.

6. Routine practices and transmission-based precautions for preventing the transmission of infection in health care. Can Commun Dis Rep 1999;25 Suppl 4:1-142. Available: www.phac-aspc.gc.ca/publicat/ccdr-rmtc/99pdf/cdr25s4e.pdf (accessed 2009 Apr. 3).

7. Siegel JD, Rhinehart E, Jackson M, et al.; Healthcare Infection Control Practices Advisory Committee. Management of multi-drug resistant organisms in health care settings, 2006. Available: www.cdc.gov/ncidod/dhqp/pdf/ar/MDROGuideline2006.pdf (accessed 2009 Apr. 3)

8. Siegel JD, Rhinehart E, Jackson M, et al.; Healthcare Infection Control Practices Advisory Committee. Guideline for isolation precautions: preventing transmission of infectious agents in healthcare settings 2007. Available: www.cdc.gov /ncidod/dhqp/gl_isolation.html (accessed 2009 Apr.14).

9. Saiman L, Siegel J. Infection control recommendations for patients with cystic fibrosis: microbiology, important pathogens, and infection control practices to prevent patientto-patient transmission. Infect Control Hosp Epidemiol 2003;24(Suppl):S6-52. 
10. Sherertz RJ, Bassetti S, Bassetti-Wyss B. "Cloud" health care workers. Emerg Infect Dis 2001;7:241-4.

11. Johnston CP, Cooper L, Ruby W, et al. Epidemiology of community-acquired methicillin-resistant Staphylococcus aureus skin infections among healthcare workers in an outpatient clinic. Infect Control Hosp Epidemiol 2006;27:1133-6.

12. Bifero AE, Prakash J, Bergin J. The role of chiropractic adjusting tables as reservoirs for microbial diseases. Am J Infect Control 2006;34:155-7.

13. Atta MG, Eustace JA, Song X, et al. Outpatient vancomycin use and vancomycinresistant enterococcal colonization in maintenance dialysis patients. Kidney Int 2001;59:718-24

14. Smith TL, Iwen PC, Olson SB, et al. Environmental contamination with vancomycin-resistant enterococci in an outpatient setting. Infect Control Hosp Epidemiol 1998;19:515-8

15. Grabsch EA, Burrell LJ, Padiglione A, et al. Risk of environmental and healthcare worker contamination with vancomycin-resistant enterococci during outpatient procedures and hemodialysis. Infect Control Hosp Epidemiol 2006;27:287-93.

16. Mayer RA, Geha RC. Helfand MS, et al. Role of fecal incontinence in contamination of the environment with vancomycin-resistant enterococci. Am J Infect Control 2003;31:221-5

17. Levy DG, Stergachis A, McFarland LV, et al. Antibiotics and Clostridium difficile diarrhea in the ambulatory care setting. Clin Ther 2000;22:91-102.

18. Kramer A. Schwebke I, Kampf G. How long do nosocomial pathogens persist on inanimate surfaces? A systematic review. BMC Infect Dis 2006;6:130.

19. Centers for Disease Control and Prevention. Recommendations for preventing transmission of infections among chronic hemodialysis patients. MMWR Recomm Rep 2001;50:1-32.

20. Centers for Disease Control and Prevention. Guideline for hand hygiene in healthcare settings. Atlanta (GA): Healthcare Infection Control Practices Advisory Committee, HICPAC/SHEA/APIC/IDSA Hand Hygiene Task force; 2002. p. 1-44.

21. World Health Organization. WHO guidelines on hand hygiene in health care (advanced draft): a summary. Geneva: The Organization; 2005. Available: www.who.int/patientsafety/events/05/HH_en.pdf (accessed 2009 Apr.14).

22. Kaplan SL. Treatment of community-associated methicillin-resistant Staphylococcus aureus infections. Pediatr Infect Dis J 2005;24:457-8.

23. Sehulster LM, Chinn RYW, Arduino MJ, et al. Guidelines for environmental infection control in the health care facilities. Recommendations from CDC and the Healthcare Infection Control Practices Advisory Committee. Chicago (IL): American Society for Healthcare Engineering and American Hospital Association; 2004.

24. Gerding DN, Muto CA, Owens RC Jr. Measures to control and prevent Clostridium difficile infection. Clin Infect Dis 2008;46(Suppl 1):S43-9.

25. American Academy of Pediatrics, Committee on Infectious Diseases. Infection prevention and control in pediatric ambulatory care. Pediatrics 2007;120:650-65.

26. Canadian Pediatric Society, Infectious Diseases and Immunization Committee. Infection control in pediatric office settings. Paediatr Child Health 2008;13:408-19.

27. Larson EL, Early E, Cloonan P, et al. An organizational climate intervention associated with increased handwashing and decreased nosocomial infections. Behav Med 2000;26:14-22.

28. Evans HL, Shaffer MM, Hughes MG et al. Contact isolation in surgical patients: A barrier to care? Surgery. 2003;134:180-8.

29. Stelfox HT, Bates D, Redelmeier D. Safety of patients isolated for infection control. JAMA 2003;290:1899-905.

30. Klein BS, Perloff WH, Maki DG. Reduction of nosocomial infection during pediatric intensive care by protective isolation. N Engl J Med 1989;320:1714-21.

31. Cohen E, Austin J, Weinstein M, et al. Care of children isolated for infection control: a prospective observational cohort study. Pediatrics 2008; 122:e411-5.

32. Madan AK, Raafat A, Hunt JP, et al. Barrier precautions in trauma: Is knowledge enough? J Trauma 2002;52:540-3.

33. Ofner M, Lem M, Sarwal S, et al.; SARS Investigative Team, CDC. Cluster of severe acute respiratory syndrome cases among protected health care workers Toronto, April 2003. Can Commun Dis Rep 2003;29:93-7.

Correspondence to: Dr. Anne G. Matlow, Hospital for Sick Children, 555 University Ave., Toronto ON M5G 1X8;

fax 416 813-4992; anne.matlow@sickkids.ca

\section{Articles to date in this series}

- Nicolle L, Conly JM, MacDonald N. Embracing ecology to limit antimicrobial resistance. CMAJ 2009;180:371-2.

- Mulvey MR, Simor AE. Antimicrobial resistance in hospitals: How concerned should we be? CMAJ 2009;180:408-15.

- Patrick DM, Hutchinson J. Antibiotic use and population ecology: How you can reduce your "resistance footprint." CMAJ 2009;180:416-21.

- Johnston BL, Bryce E. Hospital infection control strategies for vancomycin-resistant Enterococcus, methicillin-resistant Staphylococcus aureus and Clostridium difficile. CMAJ 2009; 180:627-31.

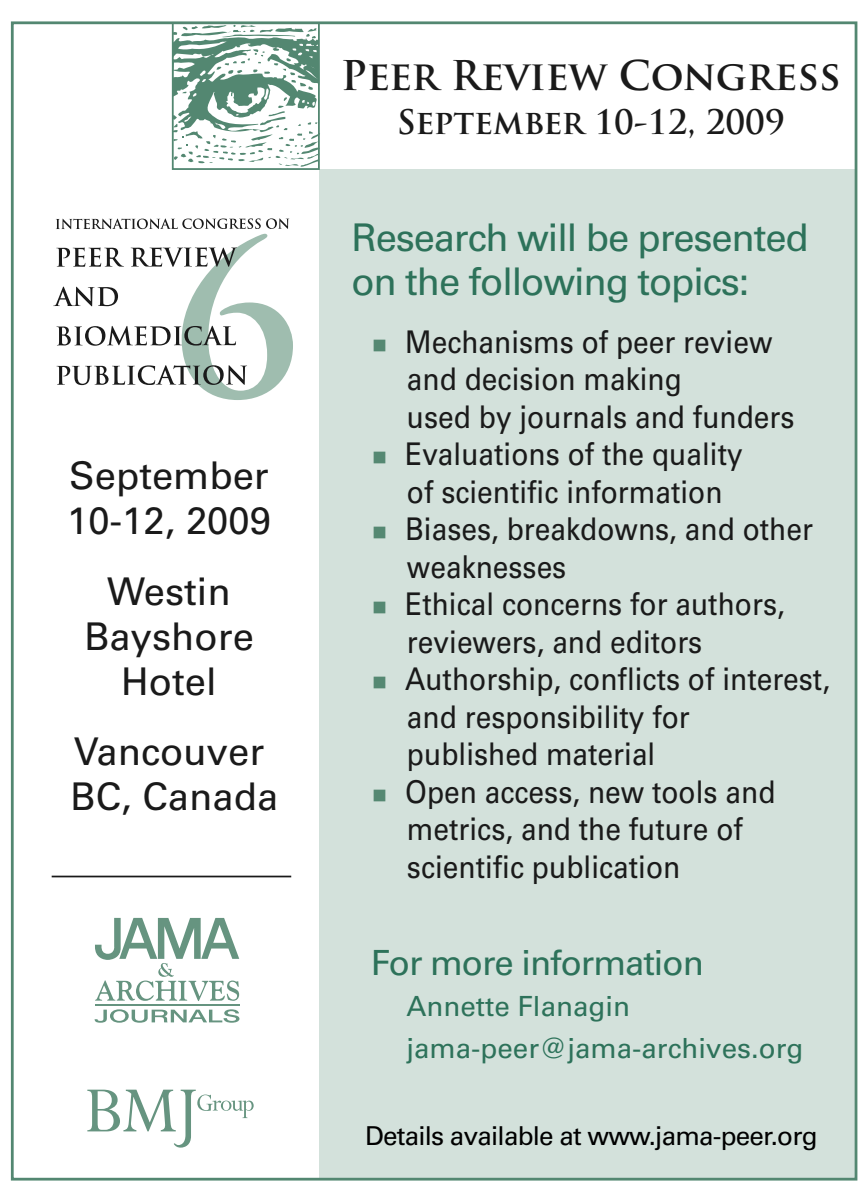

